\title{
WOCHE FÜR WOCHE
}

\section{Driver Assistance}

\section{Liebe Leserin, lieber Leser,}

für viele von uns endet am Freitagnachmittag die Arbeitswoche. Das heißt also endlich: Zeit für mich! Zeit für mich ist lebensnotwendig, damit ich wachsen, Substanz gewinnen, mich regenerieren, mich auch korrigieren, aus lebensstörender Unordnung in lebenserhaltende Ordnungen einschwingen kann. Es ist gar nicht so entscheidend, was ich in dieser Zeit im einzelnen tue. Es kommt nur darauf an, aus der Hektik, in die ich immer wieder hineingerate, auszusteigen und mich dem Lebensstrom in meinem Innern anzuvertrauen.

Ich brauche kein schlechtes Gewissen zu haben, wenn ich dabei sogenannte Pflichten hintanstelle, im Gegenteil: Mein Gewissen müsste mich zur Selbsterhaltung geradezu anspornen gegen eine falsch verstandene Opfermoral. Opfer, Hingabe heißt, sich für andere einsetzen; sich opfern sollte aber nicht heißen: Durch eigene Vernachlässigung sich selbst zerstören. Selbsterhaltung verlangt: Sich Zeit nehmen, zuweilen auch Zeit stehlen.

Ich darf mir diese Pausen gönnen, weil pflichtbewusstes Funktionieren eben nicht „alles“ ist. Weil wir alle zuzeiten nicht nur das Beschwichtigen unseres Atems wie unseres Herzschlags, sondern auch das Atemholen unserer Seele brauchen, um lebensfähig zu bleiben. Weil wir, ausgeruht und erholt, oft von selbst wieder Antrieb, ja, Freude zum Tun verspüren.

Unser Leben ist in einen großen und rhythmischen Zusammenhang hineinverwoben. Wir erfahren diesen im Herzschlag, im Ein- und Ausatmen, im Schlafen und Wachen. Wir erfahren den Rhythmus von Tag und Nacht, Sommer und Winter, Wärme und Kälte, Regen und Sonnenschein. Im Arbeiten und Ruhen, Arbeiten und Entspannen, Geben und Nehmen, im Zeithaben für andere und im Zeithaben für uns selbst finden wir diesen uns bewahrenden und erhaltenden Rhythmus.

Es gibt Menschen, die ihren baldigen Ruhestand als Abschieben aufs Abstellgleis betrachten. Gerade dieser Ruhestand gibt uns aber die Möglichkeit, langsamer zu tun, Neues zu wagen, uns mehr Besinnung zu gönnen, uns Zeit zu lassen: Zeit zum Leben. Daran sich zu erinnern, scheint mir gerade am Beginn der Urlaubs- und Sommerzeit wichtig zu sein!

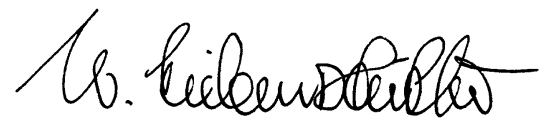

\section{WOLFGANG SIEBENPFEIFFER,}

Chefredakteur und Herausgeber Wiesbaden, im Mai 2012

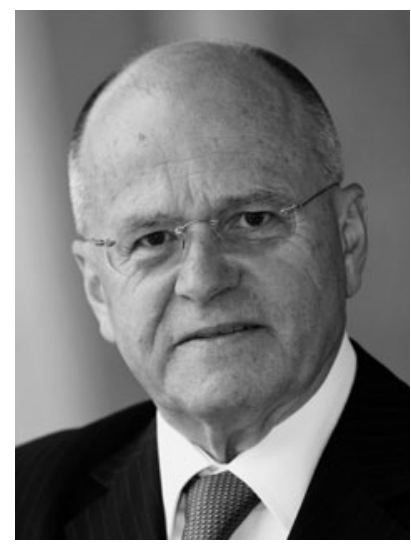

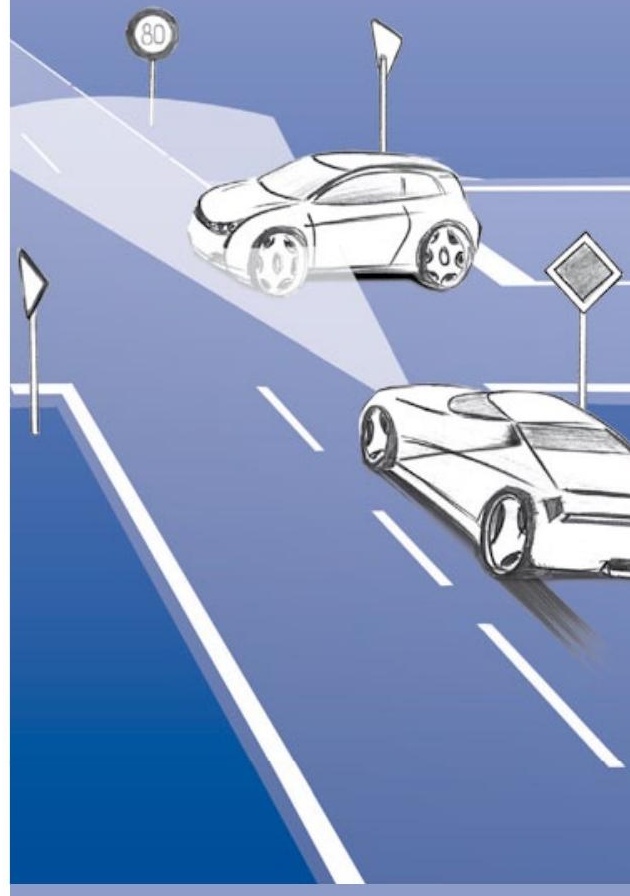

Entwicklung von Fahrerassistenzsystemen

- Offene Simulationsumgebung mit Umgebungsverkehr, 3D-Straßenmodell, Sensormodell, Echtzeit-Animation u.v.m.

- Für sensor- oder kamerabasierte Systeme, Car2X Kommunikation und Energiemanagementfunktionen

- Virtuelle Testfahrten für Steuergerätetests in MiL-, SiL- und HiL-Umgebungen

Top-Simulationsjobs Mehr erfahren und bewerben: www.tesis-dynaware.com/jobs 